\title{
Erratum to: A measure of inferential-role preservation
}

\author{
A. C. Paseau ${ }^{1}$
}

Received: 31 March 2015 / Accepted: 31 March 2015 / Published online: 9 April 2015

(C) Springer Science+Business Media Dordrecht 2015

\section{Erratum to: Synthese DOI 10.1007/s11229-015-0705-5}

In line 3 of footnote 8 on page 4, 'allow' should be 'disallow'.

In line 8 of page $5, F_{1}$ should be $\Phi_{1}$ and $F_{2}$ should be $\Phi_{2}$. Similarly for lines $1,2,3$, $7,8,13$ and 14 of page 6 .

The entry in row 20 column 6 of the table on page 5 should be 1 rather than 0 .

The entry $\exists \forall x F x$ in row 30 column 5 of the table on page 5 should be $\forall x F x$.

In line 27 of page 13, 'it' should be 'them'.

Four lines from the end of section 12.3 on page 20, 'premisses' should be 'premiss sets', and $\left\{\exists_{\geq n}\right.$ is a natural number $\}$ should be $\left\{\exists_{\geq n}: n\right.$ is a natural number $\}$.

In line 4 of footnote 30 on page 20, $Q_{0}=P_{1}$ should be $Q_{0}=\left\{P_{1}\right\}$.

The online version of the original article can be found under doi:10.1007/s11229-015-0705-5.

$凶$ A. C. Paseau

alexander.paseau@philosophy.ox.ac.uk

1 Wadham College, Oxford University, Oxford OX1 3PN, UK 